\title{
Chapter 27: Promoting Student Resilience and Wellbeing: \\ Asia-Pacific Resilient Children and Communities Project
}

(6036 words)

\section{Authors: Dr Jing Sun, MEd PhD \\ Prof Donald E. Stewart, MA, MPH, PhD}

\author{
School of Public Health, Griffith University, Australia
}

Resilience is related to many areas of a child's life, such as family relationships academic performance, peer relationships, behaviour and social skills. An understanding of the significance of resilience processes is of great value in determining approaches to preventing negative development outcomes, thereby enhancing wellbeing and learning. Individual characteristics, such as high self-esteem and self-concept have been repeatedly identified as protective factors that help to promote student learning and minimize the negative effects of risks. Connection to school is also an important protective factor. This can be defined as the experience of caring about school and a positive relationship to the school environment and school staff. Strong connectedness to school exerts a powerful influence in the lives of students. Relationships between students and teachers have been positively associated with students' motivation, achievement, feelings of belonging and affect in school. Students with higher levels of school connectedness report significantly lower levels of psychological problems, suicidal thoughts, suicide attempts, violent behaviour, substance use, and undesirable sexual behaviours. The purpose of this chapter is to explore the association between resilience and wellbeing, based on evidence from the 'Asia-Pacific Resilient Children and Communities' Project. The main research findings derived from the study were: (1) low resilience scores predispose individuals to mental health risks. (2) an intervention program using a holistic school approach to promote resilience factors such as self-esteem, self-efficacy and school connectedness significantly promotes student wellbeing and prevents mental health problems. 


\section{Introduction}

There is concern at the increasing global prevalence of mental ill health in children, estimated at 20-30\% (Stephens, Dulberg, \& Joubert, 1999). In the Asia-Pacific region, China is no exception to this trend with an estimated 15-20\% of children having mental health problems (Y. X. Sun, 2003). Many children have multiple mental and emotional problems (Chen, Chen, Kaspar, \& Noh, 2000; Tseng et al., 1988), which are inadequately treated and may be undetected (Chen et al., 2000; China Internet Information Center, 2003; Falbo \& Poston, 1993).

Numerous programs have been developed to reduce or alleviate problem behaviour or disorders and/or assist positive youth development (Browne, Gafni, Roberts, Byrne, \& Majumdar, 2004), with the majority of these intervention programs focused on behaviour, or treating child mental health disorders and symptoms such as attentiondeficit hyperactivity. However, over recent decades, a holistic approach has received increasing emphasis, underpinned by Bronfenbrenner's ecological theory (Bronfenbrenner, 1979, 1989), and supported by the World Health Organization (WHO, 1995 - Global School Health Initiative). Despite a growing body of evidence indicating that both individual characteristics and school environment plays a critical role in children's development, relatively few programs have accepted the significance of a comprehensive, universal context-focused approach (Browne et al., 2004), although a growing body of research has confirmed associations between individual resilience factors and children's social-contextual experiences in schools and mental health. 
Research demonstrates the impressive potential of programs that identify and strengthen resilience skills in at-risk youth before they have developed to the point at which intensive treatment and rehabilitation is required (Grotberg, 1995; Grotberg, 1996; Smith, Lizotte, Thornberry, \& Krohn, 1997; Wang, 1998). For this reason, practitioners and scholars are beginning to focus on health promotion approaches to help create the conditions conducive to the development of resilience in youth. In particular, there is growing recognition that we need programs located directly in the natural ecological and developmental context where children grow up and that bridge the different worlds that children inhabit.

The Asia-Pacific Resilience Project (APRP) is a health promotion project that is both theory and research-based, addressing academic success, emotional wellbeing and mental health in students in primary schools. APRP is built on a "resilience approach" to mental and emotional health and for the past 5 years has built a framework and practice for all primary school students, including at-risk students.

\section{Development of the Asia-Pacific Resilience Project}

The APRP was initially developed in response to a tender from Health Promotion Queensland (HPQ), now a unit in Queensland Health. Initially a Ministerial Advisory Committee, HPQ was funded to support projects that addressed significant and emerging health issues in Queensland. Traditionally, researchers interested in prevention or early intervention programs spotlighted clinical measures of mental health status as key indicators of poor mental health outcomes. HPQ recognised that such an approach fails to determine "upstream” risk factors that, if addressed through effective early intervention or preventative strategies, directly and indirectly 
determine clinical outcomes. Additionally, this approach neglects measures of social indicators that reflect the "capital” of a community, which also determines clinical outcomes.

This project is based on a model that suggests monitoring upstream indicators, such as the capacity of individuals and communities to withstand the negative consequences of adverse circumstances, is critical. This is because such measures can reasonably predict subsequent demand for intervention services, whilst also reflecting the wide array of contextual determinants known to have an impact on health outcomes (Mazza \& Reynolds, 1999). By fostering the development of personal strengths, or human capital, as well as building social systems that provide healthful environments (social, political, and organisational), the longer-term need for interventions may be reduced. The model identified to incorporate this theoretical perspective and to allow the planning, development and management of a resilience-based intervention was the WHO 'health promoting school' model (World Health Organization, 1996). Such a model is predicated upon a socio-ecological or holistic perspective but it also has its foundations in what Antonovsky (Antonovsky, 1987) termed a 'salutogenic' or health-building approach.

The APRP was therefore constructed upon a socio-ecological paradigm of health and sought to explain the interdependence between the school as a social system or setting and population health outcomes. This model reflects a commitment to the concept of 'place' (or habitus) and its significance to health and wellbeing at both individual and population levels. This approach recognises that intrapersonal characteristics, life experiences and dimensions of settings combine to determine our personal capacities 
for survival in an increasingly complex and unpredictable world (Berkman, Glass, Brissette, \& Seeman, 2000; Grossman et al., 2003; Shahar \& Priel, 2002; Svanberg, 1998)

The APRP was developed recognizing that no theory of resilience currently encompasses the multiple systemic influences upon an individual's development of resilience - the family, peer group, school, or community - and that interventions typically address risk and protective factors within one setting and ignore the potential interactive effects, whether these be additive or subtractive, from other systems of influence.

The Project commenced in Queensland in 2003 with 10 intervention schools (north Brisbane) and 10 control schools (south Brisbane). It was supported by a Project team including Project officers, researchers, funding support to the intervention schools, together with extensive workshops and in-service support for teachers, students and parents. As part of a strategy to ensure the research community was kept informed of progress, regular papers and posters were presented at national and international conferences.

At one of these conferences, delegates from China expressed interest in addressing some of the perceived mental health issues observed in their home Provinces, using the resilience approach. Colleagues in China were keenly interested in the issue of resilience, due to an increasing concern with mental ill-health associated with rapid change in China, including urbanization, globalization, high levels of competition, and potential social and behavioural stresses due to high expectations from parents 
and grandparents. The evidence available regarding the effectiveness of the health promoting school approach in dealing with mental health promotion has led to enthusiastic endorsement of this approach from school principals, staff and students in the cities of Nanjing, Hefei, Shenzhen, and Shenyang.

There is a high rate of mental health problems amongst children and adolescents in China, with about 1 in 6 children (Lee, 2004) and adolescents experiencing negative emotional feelings. Suicide in association with depression is now the primary cause of death for youth, with the age for suicide and attempted suicide continually falling (Parker, Gladstone, \& Chee, 2001). A recent study indicates that 30\% of 'normal' Chinese adolescents reported having depression and 41\% indicated anxiety (Hesketh, Qu, \& Tomkins, 2003). Children with these 'invisible' mental health problems often go unrecognised for a prolonged period. However, currently, there is no generally accepted mental health promotion model developed for children in China.

In 2005, training workshops were held for school staff in Nanjing and Hefei that clearly showed the relevance of the project to the needs of children, families and schools in China. The experience in Nanjing and Hefei was broadly publicised and subsequently attracted Shenzhen city (Guangdong Province) and Shenyang city (Liaoning Province) health and education officials to participate in the project, to meet the mental health promotion needs of children, families and schools in their cities. The two week long training workshops with approximately 40 primary school staff and parents as participants, were conducted in each city dealing with: (1) the principles of HPS approach, (2) resiliency and mental health issues. Six-monthly training workshops were also conducted by our Chinese collaborating institutions in 
each city. The schools in each city participated in health promoting activities, using intervention material designed for the study.

A prospective intervention study design was used, with intervention schools matched to control schools in terms of school size and socio-economic status. The study plan was designed to compare the intervention effects on intervention schools in terms of resilience, family functioning, school organization and climate, community social support, health promoting school features, and social capital. A time series design was used, with pre- and post- intervention comparisons for both intervention and control schools, to examine the intervention effects over time.

The HPS intervention group was comprised of selected primary schools in each city with a cohort of school age children from year 1 to 6 using HPS approach. The control group was comprised of primary schools with a cohort of school age children from year 1 to 6 who were matched with the intervention group in grade, school socio-economic status level, education quality level and school size.

The intervention schools consisted of:

- 5 primary schools in Nanjing,

- 2 primary schools in Hefei,

- 2 primary schools in Shenzhen,

- 4 Primary schools in Shenyang.

These schools were matched with a similar number of control schools. In all, there were 13 intervention schools and 13 control schools in four participating cities.

A multi-level strategy was devised, consisting of three levels: 
(1) Level 1: whole school approach to promote student resilience; a supportive school environment; family functioning; community involvement

(2) Level 2: teacher support and peer support group for children who encounter problems during school days.

(3) Level 3: psychological counseling and individual help for children who have psychological problems using psychological counseling service provision.

\section{Development of Resilience}

Research into resilience began around 40-50 years ago when the concept was initially clinically formulated and analyzed in a clinical setting. Early investigations by Werner and Smith (1982) reported on a 30-year ethnographic study of high-risk children in Kauai. This study followed a cohort of children, born in 1955 in Kauai, Hawaii, into troubled and impoverished families. Werner and Smith discovered that one-third of the high-risk children were vulnerable, but succeeded both in school and later at work. The other two-thirds developed emotional and behavioural problems including delinquency, teenage pregnancy and mental health problems.

Werner and Smith found that the successful group could be distinguished by certain temperamental characteristics and social skills; strong relationships with parents or other adults; and support within the community. Of those teenagers who developed problems, some matured to become successful adults. This group tended to have pivotal experiences with supportive people in situations that structured their lives. For example, those who joined the military or a church group, went to college or 
developed a stable and close relationship with another person were more likely to succeed. These characteristics were labelled "protective factors" and provided a buffer as well as a reservoir of resources to deal effectively with stress (Resnick, 1997). More recently, Conger and Elder (1994) found similar results in a 10-year prospective study of a cohort of 558 young people and their families. Resilience to economic hardship was promoted by support from parents, siblings, and adults outside the family.

Resilience has been used to characterise individuals who overcome difficult and challenging life circumstances and risk factors (Garmezy, Masten, \& Tellegen, 1984; Rutter, 1984; Werner, 1992). This perspective has conceptualised resilience as successful adaptation despite risk. Risk factors have been defined as hazards relating to the individual, or to the individual's environment, that increase the likelihood of a problem occurring (Rutter, 1987).

Resilience has been described as the interaction between risk and protective factors, specifically a process that results from individual reaction to risk factors, or vulnerabilities, that are present in the environment (Luthar, 2003; Luthar \& Cicchetti, 2000). Studies on resilience in terms of adaptation despite risk often cite protective factors to explain why only the minority of children living in adverse conditions manifest problem behaviours and symptoms of psychopathology (Rutter, 1987). Protective factors have been referred to as those factors in the individual, or the environment, which enhance an individual's ability to resist problems and deal with life's stresses. Thus, protective factors exert their effect only when a risk is present 
(Rutter, 1987). Protective factors have been considered to either compensate the risk, or buffer the effect of risk on child development.

Antonovsky’s (Antonovsky, 1987, 1996) salutogenic model focuses on factors that help identify coping resources of children which may contribute to resilience and effective adjustment, notwithstanding adversity and risk. The concepts implicit in the salutogenic model have relevance in health promotion and practice. A salutogenic model, as opposed to a pathogenic model, emphasizes competence and healthy children functioning in multiple domains (e.g. social, emotional and academic) and emphasises enhancing protective factors in the lives of all children, irrespective of the risk present. Implicit in this approach is the idea that resilience in children can be fostered and promoted by establishing protective factors in the environment (Benard, 2004).

The emphasis on resilience toward an ecological approach takes into account the influences of social context, both proximal and distal, to children (McLoyd, 1998). This advance is formalized in Bronfenbrenner's ecological model (Bronfenbrenner, 1979, 1989). It specifies that wellbeing is affected substantially by the social contexts in which children are embedded and is a function of the quality of relationships among individual, family and institutional systems. The factors that reside within the individual include a variety of coping skills; for example self-efficacy, self-esteem, problem solving and communication and cooperation. Factors external to the individual considered as protective factors include parental support, teacher mentoring, or school support that promotes positive youth development. The term 'external' emphasizes the social environmental influences on child health and development and 
helps to place resilience in a more ecological context, moving away from conceptualization of resilience as a static, individual trait.

Although there is no overall consensus regarding the definition of the resilience paradigm, there is a general agreement regarding its construct and components. These include individual characteristics of the child, family structures and the external environment (Werner, 1989). Werner argues that resilient children have the following characteristics: a high level of autonomy, empathy, better problem solving skills and supportive peer relationships. He also found that variables relating to resilience are protective factors embedded in the family, the school and the community (Werner, 1992). Protective factors modify, ameliorate, or alter a person's response to the negative effects of risk (C. Smith \& Carlson, 1997). Family protective factors are those that shape the family's ability to endure in the face of adversity and risk. Key characteristics of family protective factors include warmth, affection, cohesion, commitment and emotional support for one another (M. A. McCubbin, McCubbin, \& Thompson, 1987). These factors have also been found to be associated with resilience in children (Smith, 1999; Werner, 1995). School experiences that include a safe and supportive environment, positive peer relationships, positive teacher influences, and opportunities for success, have also been found to be positively related to children's resilience (Rutter, 1987; Werner, 1995). Such variables may have a decisive impact on a child's ability to cope with stress or challenge and may be crucial in determining the extent to which a stressful situation will escalate into harm or resolve itself into adjustment and resilience. Community support includes participation in the activities of pro-social organisations, such as clubs, or scouts. It also includes neighbourhoods possessing high collective efficacy (high levels of social cohesion and informal social 
control); a high level of public safety; effective emergency social services; and good public health and health services. Thus, the presence of protective factors may determine a child's ability to adjust and cope with adversity in the family, school or community.

Researchers have commonly assigned resilience related factors into two broad categories: 1) those falling within the domains of individual personality attributes or dispositions (Rutter, 1990; Werner, 1992) such as social competence, problem solving, autonomy, and sense of future and purpose; and 2) those relating to environmental influences such as peers, family, school and local community (Rutter, 1987; Werner, 1995).

\section{Resilience and student wellbeing}

Numerous studies indicate that most threats to the development of children are those derived from adversities that undermine the basic human protective systems for development. The APRP attempted to promote resilience by focusing on preventing damage to these basic protective systems. Effective schools were believed to be those where there are strategies that are likely to help children to overcome challenges and achieve resilient outcomes and trajectories. Interventions that promote effective teaching and learning and engagement of committed parents, teachers, and community members in the lives of children are also critical.

Primary school education is directly concerned with resilience because of its twofold focus on risk and positive adaptation. Firstly, its focus is on the development of competence among young people, including those who have encountered adversity. It 
is estimated that more than $20 \%$ of children in China, Australia and U.S., especially those in urban environments, are at risk for school failure and significant social, emotional, and behavioural problems, such as depression, anxiety, aggression, suicide, and unhealthy risk taking (Ellickson, McGuigan, Adams, \& Bell, 1996; Lau, Chan, \& Lau, 1999; Sawyer et al., 2000; Zhang, Ji, \& Yan, 1997). As research demonstrates, many children face multiple and interacting risks in their families, communities, peer groups, and school environments (Cicchetti \& Toth, 1996; Luthar \& Cicchetti, 2000). Without intervention, young people confronting multiple adversities have a greater risk of developing substantial problems and dysfunctions along their developmental pathways.

Secondly, in organizational terms, schools are confronting problems and needs of immense scope, for which they are largely unprepared. School resources are limited, making it a challenge for them to address many students' needs. Yet, without intervention coordinated by schools or community agencies, young people are unlikely to receive the required help. Schools are important settings for prevention, health promotion and intervention and are the setting where most developmental intellectual, social, emotional and physical tasks engage and transform children.

\section{Development of Resilience Measures}

The criteria used to define resilience relating to students included, firstly, successful individual adaptation (e.g., self-esteem), and secondly, a sufficiency of provision of external support from family, school and community at context level. 
The APRP, which was mainly exploratory in nature, had two main purposes, one methodological, the other practical. First, from within the general conceptual framework of the resilience approach, we wished to devise a new and feasible method for identifying resilient outcomes among primary school children in primary schools. Second, we wanted to explore the effectiveness of a resilience approach to promote student wellbeing, based on a number of outcome measures chosen from among some of the main resilience dimensions. The main instruments through which APRP attempted to define and measure resilience was via three questionnaires: a Student Resilience, a Parent or Caregiver Resilience, and a Staff Resilience instrument.

At the student level, resilience measurement in relation to the personal characteristics examined in this study were drawn from the relevant literature. They included selfesteem, self-efficacy, capacity to solve problems, willingness to cooperate and communicate, sense of purpose in life, autonomy, and perceptions of family, peers, school and community (Rutter, 1990; Werner, 1992). Family-level variables examined focussed on family functioning, family coherence and how the family as a unit copes with the stresses of life. Family coherence pertains mainly to the elements of coping, problem solving, support, communication and understanding (Rutter, 1990; Werner, 1992). Resilient families generally have the resources to access support from the community, friends, and kinship network. At the school level, variables examined included parental perceptions of the school organisational environment, its capacity to provide good structure, clear rules and regulation, and the extent to which a supportive psychosocial environment was present in the school. Numerous studies have indicated that social support has the ability to moderate the effects of family stress (DuBois, Felner, Meares, \& Krier, 1994; Murata, 1994; Spilman, 2006); hence, 
community level variables in the study examine social support as perceived by parents/caregivers. The family stress and coping literature is replete with emphasis on the importance of social support both as a protective factor and as a recovery factor. Such community, friend and kinship networks can help to give meaning to a situation, help to develop coping strategies, and, more importantly, foster the family's ability to face challenge and change situations (H. I. McCubbin, Paterson, \& Glynn, 1987).

A number of school factors have been identified as being able to influence children's mental health. Specifically noted is the school ethos, climate or environment; the curriculum, the rules and discipline regarding management of student behaviour, expectations of the staff and parents, and opportunity for positive relationships with adult models in the school (Baker, Dilly, Aupperlee, \& Patil, 2003). The school-level variables examined also included staff perceptions of the school's health promoting nature and social capital. Other researchers have identified similar health promoting school factors including school policy, school physical environment, and school social environment but have also identified personal skill building, access to health service, and school-community relations (Booth \& Samdal, 1997; Deschesnes, Martin, \& Hill, 2003; Rogers, Moon, Mullee, Speller, \& Roderick, 1998; Scriven \& Stiddard, 2003) to be important aspects of the health promoting school environment.

The intervention strategies using socio-ecological, health promoting school principles in intervention schools emphasised related themes, as summarised in the Table below.

Intervention activities 


\begin{tabular}{|c|c|}
\hline $\begin{array}{l}\text { Professional } \\
\text { development for staff } \\
\text { and parents }\end{array}$ & $\begin{array}{l}\text { Run workshop and training for staff and parents in } \\
\text { - } \quad \text { Resilience } \\
\text { - Parenting skills in relation to parent-student relationship } \\
\text { development, communications between school and } \\
\text { families, parental engagement in school activities }\end{array}$ \\
\hline $\begin{array}{l}\text { Student resilience } \\
\text { building }\end{array}$ & $\begin{array}{l}\text { Through various activities and curriculum to develop } \\
\text { students: } \\
\text { - Problem solving skills } \\
\text { - Social skills } \\
\text { - Communication skills } \\
\text { - Peer relations } \\
\text { - Assertiveness skills }\end{array}$ \\
\hline School environment & $\begin{array}{l}\text { Decoration of school to develop physical and social } \\
\text { environment to address issues of: } \\
\text { - Safety } \\
\text { - Anti-bullying } \\
\text { - Friendship } \\
\text { - Respect } \\
\text { - Good student-teacher relationship } \\
\text { - Good student relationship } \\
\text { - Assembly to celebrate success and give awards to } \\
\text { students with good behaviours and social-emotional } \\
\text { competence. }\end{array}$ \\
\hline $\begin{array}{l}\text { Community } \\
\text { partnerships }\end{array}$ & $\begin{array}{l}\text { Intervention schools build partnerships with: } \\
\text { - } \quad \text { local communities } \\
\text { - } \quad \text { Psychological associations } \\
\text { - } \quad \text { Police office } \\
\text { - } \quad \text { Parent association } \\
\text { - } \quad \text { Youth club }\end{array}$ \\
\hline $\begin{array}{l}\text { Curriculum } \\
\text { development }\end{array}$ & $\begin{array}{l}\text { Resilience issue is addressed in key learning areas: } \\
\text { - } \text { Maths } \\
\text { - } \text { Literacy } \\
\text { - } \text { English } \\
\text { - } \text { Health and social study } \\
\text { - } \quad \text { Sports }\end{array}$ \\
\hline $\begin{array}{l}\text { Extra-curricula } \\
\text { development }\end{array}$ & $\begin{array}{l}\text { The resilience skills were addressed through extra- } \\
\text { curriculum activities: } \\
\text { - Excursion } \\
\text { - Family activities such as BBQs, picnics } \\
\text { - Parent-student activities }\end{array}$ \\
\hline $\begin{array}{l}\text { Psychological } \\
\text { counselling }\end{array}$ & $\begin{array}{l}\text { - Develop psychological counselling centre: provide } \\
\text { psychological support when students need help } \\
\text { - Referral service: liaise with local psychological } \\
\text { counselling service when students have behavioural and } \\
\text { emotional problems. }\end{array}$ \\
\hline
\end{tabular}


The APRP strived to overcome the traditional distinctions between mental health and educational practice in work with students. The project shows that academic success acts as a protective factor for at-risk youth, providing them with a sense of selfefficacy and tools for life success. Thus, in a virtuous cycle, as academic success increases, the risk for delinquent student behaviours decreases, and as risky behaviours decrease, academic progress begins to improve. Prevention and intervention then comes not only from outside schools but also from within and is focused on eradicating the barriers that obstruct students' learning. The fact that the Project fully incorporated educational goals in schools supports its success. Teachers, parents and principals viewed the project as supporting the learning goals of the schools rather than as a distraction from their primary goals.

The APRP was designed with the concept of partnership at its core, to work with schools to maximise health and thereby contribute to the achievement of learning outcomes. In terms of planning, management, implementation and evaluation, the Project illustrated the vital significance of collaborative structures, partnerships, comprehensive and integrated approaches, as well as consistent, integrated, multidisciplinary, coordinated approaches when dealing with health issues for children and young people. The Project provided evidence to intersectoral awareness of the developmental, social and health needs of children and young people together with an example of effective, evidence-based and collaborative action to address the mental health and developmental issues of children and young people. It also illustrated a model that can strengthen existing formal and informal links and partnerships with other sectors as well as support a family-centred and setting/place-based approach. 
Also, as an important educational objective, it allowed opportunities for young people to participate in the planning, implementation and evaluation of developmental, social and health interventions.

One of the research questions addressed by the Project was the relationship between resilience and depression, as depression may affect many areas of a child's life in the school, such as diminished academic performance (Kovacs \& Goldston, 1991), poor peer relationships (Connolly, Geller, Marton, \& Kutcher, 1992), conduct problem and socialised delinquency (Norvell \& Towle, 1986), suicide (Phillips et al., 2002), and disturbed family relationships (Hamilton, Asarnow, \& Tompson, 1997). Sub-clinical depression must also be taken seriously, as adolescents with sub-clinical depression have been found to be significantly more likely to develop clinical disorders over a subsequent period of two years (Horwath, 1992). Adolescents with high self-report depression scale scores have been found to be 3 times more likely to develop depression compared to those without elevated scores.

The results indicated that a low level of resilience is significantly related to depression symptoms. Important findings from our study extend the work of various intervention programs (Barrett, Sonderegger, \& Xenos, 2003; Cutuli, Chaplin, Gillham, Reivich, \& Seligman, 2006; Shochet et al., 2001). Firstly, constructs relating to resilience were extended to other aspects such as social support from peers, families, school and communities, in addition to individual resilience characteristics such as self-esteem. Secondly, depression is related to low level of family support; to low level of school support; and to low level of community support. To date, virtually all of the research that has examined predictors of depression in children and adolescence has focused on 
individual characteristics, such as self-esteem or self-competence. However, it is apparent that much more research needs to be conducted examining potential predictors of depression, such as social support from family, school and community, since depression and anxiety are common during adolescence (Compas, Orosan, \& Grant, 1993; Lesionsohn, Clarke, Seekey, \& Rhode, 1994; J. Sun \& Stewart, 2007). Also, gender differences in relation to anxiety problems become apparent during this time, with boys at more risk of experiencing problems than girls in primary schools.

An intervention program to reduce the depression rate in primary school children was then incorporated into the curriculum, extra-curricula activities, school policy, school ethos and environment. With regard to the prevention effect, it was expected that the intervention group would be associated with fewer depressive symptoms at the postintervention phase compared to the non intervention group and that children's resilience levels in the intervention group would also be increased. In testing these hypotheses, results show that there were significant differences between the pre- and post-intervention phase in the proportion of students who had subclinical depression symptoms in the intervention schools, and differences between intervention and controls schools in the post-intervention phase. Only $21.6 \%$ of students in the intervention schools compared to $29.4 \%$ of students in the control schools in the postintervention phase were sub-clinically depressed. From a health promotion perspective, $2.8 \%$ of sub-clinical children in the intervention schools fell into the normal category; in contrast, $8.1 \%$ of healthy children moved to the subclinical category in the control schools at post-intervention. 
These results confirm that children in the intervention schools showed a significantly greater decrease in depressive symptoms as measured by the Kovaks Child Depression Inventory (Kovacs, 1992) at the post-intervention phase. For both subclinical and clinical depression groups in the intervention schools all resilience scores significantly increased, compared with scores in the pre-intervention phase. One aspect of the findings that is difficult to interpret is that there was a significant difference between the pre- and post-intervention phase for the non depressed group in terms of resilience scores in the intervention group, such that all resilience scores except goals and aspirations decreased for the non-depressed group students. Further investigation is needed to examine if their decreasing scores in resilience factors may lead to later depressive symptoms.

Major beneficiaries of the program were those sub-clinical students who began with moderately elevated depressive symptoms. Those in the intervention program were more likely to shift into the healthy range and less likely to fall into the clinical range. There were $2.8 \%$ of students with sub-clinical depressive symptoms who moved into the normal range. These results are consistent with recent studies which have indicated that a mental health promotion intervention program is likely to be most beneficial to sub-clinical groups (Shochet et al., 2001).

The universal nature of the intervention program also appeared to be of benefit to adolescents who were initially considered healthy. That is, there was a significant difference between the pre- and post-intervention phase in the proportion of students who were in the healthy categories in the intervention group. At post-intervention, none of the healthy students moved into the sub-clinical category, however, in the 
control schools, $8.1 \%$ of healthy children moved into the sub-clinical category. This result is similar to Shochet et al's (2001) study where $10.1 \%$ of the healthy adolescents moved into the subclinical category if they were not recruited into a universal intervention program. The intervention program was, therefore, clearly beneficial to both subclinical and healthy groups. This evidence adds weight to the importance of any action taken to maximise mental health and well-being amongst populations and individuals. It also emphasises the importance of enabling people to maximise their health potential through influencing environmental conditions.

These results therefore support and renew the current emphasis on prevention and early intervention. The model used in this Project, the healthy school community (or health promoting school) model, provides a mechanism to achieve these goals. The prevention of mental health problems and mental disorders relies on reducing the risk factors for mental disorder as well as enhancing the protective factors that promote mental health. Developing social, emotional and behavioural skills using the concept of resilience to promote mental health and well-being, can be seen as both a broad preventative initiative at a population or whole school level, but also as an opportunity to identify at-risk students and help to prevent them moving to further levels of depression. The results of this study are encouraging in terms of the value of investing resources in a comprehensive intervention program, due to the prevention impact on children with subclinical depressive symptoms as well as healthy children in primary schools in China.

\section{Resilience enhancing environment and student mental health}

Numerous programs have been developed to reduce or alleviate problem behaviour or disorders and/or assist positive youth development (Browne et al., 2004), with the 
majority of these intervention programs focused on behaviour, or treating child mental health disorders and symptoms such as attention-deficit hyperactivity. The effects of an adverse social environment are likely to be cumulative. The Kauai Pregnancy Study (Werner, 1992), for example, examined the impact of perinatal stress and the quality of the environment on children's physical, intellectual, and social development. At 10 years of age, social class was found to be significantly associated with achievement, intelligence, and emotional problems. Early environmental deprivation had an even greater impact at 2 years of age than at 10 years of age, indicating that the effect increases with age. The significance of the school at this age has also been recognised in a range of studies, effects have been found of school structural variables, characteristics of school principals/teachers, and aspects of the school policy relating to student achievement and wellbeing. A growing body of evidence indicates that school environment plays a critical role in children's development. The APRP accepted the significance of a comprehensive, universal context-focused approach (Browne et al., 2004) through statistical analysis that has confirmed associations between children's social-contextual experiences in schools and mental health.

The resilience approach requires a substantial change in the way schools, their staff and students interact with each other and promote health and wellbeing. This involves moving from practices that rely mainly on classroom-based health education models to a more comprehensive, integrated construct of health promotion that focuses both on children's attitudes and behaviours, and on their environment (Stewart, Sun, Patterson, Lemerle, \& Hardie, 2004; J. Sun \& Stewart, 2007). 
To achieve maximum benefit, the APRP considered these school contextual and environmental characteristics, namely: (1) the formal health curriculum that gives school aged children the essential knowledge and social skills that will allow them to make enlightened choices affecting their physical and psycho-social health; (2) the school environment, which refers to the quality of the physical environment and the social environment, the health services and policies of the school; and (3) school/community relationships.

In terms of partnership with community health services, APRP provided evidence of a productive partnership in mental health promotion, seeking to develop protective factors by increasing the supportive environment. Most of the studies published on the effect of school health promotion policies deal with only one behaviour (such as smoking, or alcohol and drug use) with few aspects of community and intersectoral partnerships and school support system (Browne et al., 2004). Wells et al.'s review (2003) suggested that long-term interventions that promote the positive mental health of all students and involve changes to the school climate are likely to be more successful than brief, class-based mental illness prevention programs.

The intervention program using resilience approach in APRP project is to investigate the significance of the school ecology, its social and environmental characteristics, on mental health promotion, characterised as the promotion of 'resilience'. School staff indicate that they consider that there have been significant improvements in the areas of physical and social environment in relation to curriculum development focused on resilience; on mental health service provision and partnership with the community and health service providers; on mental health policy development in their schools; on 
school organisational structure; and in terms of promoting positive life experiences for students.

The study also gives strong support to the resilience approach, that links schools with relevant agencies and groups, embeds protective factors into the curriculum and encourages school members’ participation. It also indicates the opportunities available for mental health promotion through school members' involvement in the intervention. The project indicates that a resilience approach to get the whole school's participation is effective in creating a healthy mental health promotion environment within primary schools in China.

School environment indicators, such as the school social environment, schoolcommunity relations and curriculum development, were all aligned with resilience. Intervention schools, in a relatively short time scale, showed immediate effects compared with schools that were not using a holistic approach. This improvement was shown across all mental health promotion areas.

Numerous factors have the potential to influence the extent to which the physical and social environment of the school setting can influence health, broadly defined (Greenberg et al., 2003). Evidence from this study supports the contention that we focus attention on changing organisational, physical conditions and social environment rather than solely focussing on the individual. The evidence relating to the significant improvement in school organisation in the current study supports strategies that encompass the school environment, structural issues and organisational practice. Such areas should become key components of mental health promotion programs. 


\section{Conclusion and Implication in Student Wellbeing}

Over the last three decades, a holistic approach has received increasing emphasis, underpinned by Bronfenbrenner’s ecological theory (Bronfenbrenner, 1979, 1989). The APRP explored the significance of the school ecology, its social and environmental characteristics, on mental health promotion, characterised as the promotion of 'resilience'. It specifically focussed on staff reports on an intervention project that used the resilience approach to promote resilience across the whole school community in a number of cities in China. School staff indicate that they consider that there have been significant improvements in the areas of physical and social environment; in relation to curriculum development focused on resilience; on mental health service provision and partnership with the community and health service providers; on mental health policy development in their schools; on school organisational structure; and in terms of promoting positive life experiences for students.

Results from the APRP indicate that

- Resilience and contextual factor are significantly related to depression, even after demographic characteristics are controlled in the analysis.

- School organization and climate are significantly related to student mental health.

- Family functioning related to family environment is significantly related to student mental health.

- Social support related to community-family relationships and community social support for family is significantly related to student mental health. 
- Health promoting school features are significantly related to student mental health status.

These broad environmental improvements, derived from a large population based study, are strongly supported by statistical evidence. 
Antonovsky, A. (1987). Unravelling the mystery of health. San Francisco, CA: Jossey-Bass.

Antonovsky, A. (1996). The salutogenic model as a theory to guide health promotion. Health Promotion International, 11, 11-18.

Baker, J. A., Dilly, L. J., Aupperlee, J. L., \& Patil, S. A. (2003). The developmental context of school satisfaction: School as psychologically healthy environment. School Psychology Quarterly, 18(2), 206-221.

Barrett, P. M., Sonderegger, R., \& Xenos, S. (2003). Using Friends to combat anxiety and adjustment problems among young migrants to Australia: A national trial. Clinical Child Psychology and Psychiatry, 8, 241-260.

Benard, B. (2004). Resiliency: What we have learned. Retrieved 24 September 2007, from http://cye.colorado.edu/review.pl?n=206

Berkman, L. F., Glass, T., Brissette, I., \& Seeman, T. E. (2000). From social integration to health: Durkheim in the new millennium. Social Science and Medicine, 51, 843-857.

Booth, M. L., \& Samdal, O. (1997). Health-promoting schools in Australia: Models and measurement. Australian and New Zealand Journal of Public Health, 21(4), 365-370.

Bronfenbrenner, U. (1979). The Ecology of Human Development: Experiments by Nature and Design. Cambridge: Harvard University Press.

Bronfenbrenner, U. (1989). Ecological systems theory. Annals of Child Development, 6, 187-249.

Browne, G., Gafni, A., Roberts, J., Byrne, C., \& Majumdar, B. (2004).

Effective/efficient mental health programs for school-age children: a synthesis of reviews. Social Science \& Medicine, 58, 1367-1384.

Chen, X., Chen, H., Kaspar, V., \& Noh, S. (2000). Adolescent social, emotional and school adjustment in Mainland China. International Journal of Group Tensions, 29, 51-78.

China Internet Information Center. (2003). Million adolescents in China were in mental sub-health.

Cicchetti, D., \& Toth, S. L. (1996). Adolescence: Opportunities and Challenges. Rochester, NY: University of Rochester Press.

Compas, B. E., Orosan, P. G., \& Grant, K. E. (1993). Adolescnet stress and coping: implications for psychopathology during adolescence. Journal of Adolescence, 16, 331-349.

Conger, R. D., \& Elder, G. H. J. (1994). Families in troubles times. New York: Aldine de Gruyter.

Connolly, J., Geller, S., Marton, P., \& Kutcher, S. (1992). Peer responses to social interaction with depressed adolescents. Journal of Clinical Child and Adolescent Psychology, 21, 365-370.

Cutuli, J. J., Chaplin, T. M., Gillham, J. E., Reivich, K. J., \& Seligman, M. E. P. (2006). Preventing co-occurring depression symptoms in adolescents with conduct problems: The Penn Resiliency Program. Annals of the New York Academy of Sciences, 1094, 282-286.

Deschesnes, M., Martin, C. L., \& Hill, A. J. (2003). Comprehensive apoproaches to school health promotion: how to achieve broader implementation? Health Promotion International, 18(4), 387-396.

DuBois, D. L., Felner, R. D., Meares, H., \& Krier, M. (1994). Prospective investigation of the effects of socioeconomic disadvantage, life stress, and 
social support on early adolescent adjustment. Journal of Abnormal Psychology, 103(511-522).

Ellickson, P. L., McGuigan, K. A., Adams, V., \& Bell, R. M. (1996). Teenagers and alcohol misuse in the United States: By any definition, it is a big problem. Addiction, 91, 1489-1503.

Falbo, T., \& Poston, J., D. L. (1993). The academic, personality, and physical outcomes of only children in China. Child Development, 64, 18-35.

Garmezy, N., Masten, A. S., \& Tellegen, A. (1984). The study of stress and competence in children: A building block for developmental psychopathology. Child Development, 55, 97-11.

Grossman, A. W., Churchill, J. D., McKinney, B. C., Kodish, I. M., Otte, S. L., \& Greenough, W. T. (2003). Experience effects on brain development: possible contributions to psychopathology. Journal of Child Psychology and Psychiatry, 44, 33-63.

Grotberg, E. (1995, September, 27-30). The international resilience project: research, application, and policy. Paper presented at the Paper presented The Symposio International: Stress e Violencia., Lisboa, Portugal, .

Grotberg, H. (1996). The international resilience project: Findings from the research and effectiveness of intervention. Paper presented at the Annual Convention of the International Council of Psychologists, Banff, Canada.

Hamilton, E. B., Asarnow, J. R., \& Tompson, M. C. (1997). Social, academic, and behavioural competence of depressed children: relationship to diagnostic status and family interaction style. Journal of Youth and Adolescence, 26(1), 77-87.

Hesketh, T., Qu, J. D., \& Tomkins, A. (2003). Health effects of family size: cross sectional survey in Chinese adolescents. Archives of Disease in Childhood, 88(6), 467-171.

Horwath, E. (1992). Depressive symptoms as relative and attirbutable risk factor for first-onset major depression. Archieves of General Psychiatry, 49(10), 817823.

Kovacs, M. (1992). Children's Depression Inventory Manual: Multi-Health Systems.

Kovacs, M., \& Goldston, D. (1991). Cognitive and social cognitive develoment of depressed children and adolescents. Journal of American Academy of Child and Adolescent Psychiatry, 30, 388-392.

Lau, S., Chan, D. W. K., \& Lau, P. S. Y. (1999). Facets of loneliness and depression among Chinese children and adolescents. The Journal of Social Psychology, 139(6), 713-729.

Lee, M. (2004). The current state of public health in China. Annual Review of Public Health, 25(327-339).

Lesionsohn, P. M., Clarke, G. N., Seekey, J. R., \& Rhode, P. (1994). Major depression in community adolescents: Age at onset, episode duration,a nd time to recurrence. Journal of the American Academy of Child and Adolescent Psychiatry, 94, 809-818.

Luthar, S. S. (Ed.). (2003). Resilience and vulnerability: Adaptation in the context of childhood adversities. New York: Cambridge University Press.

Luthar, S. S., \& Cicchetti, D. (2000). The construct of resilience: Implications for interventions and social policies. Development and Psychopathology, 12, 857885. 
Mazza, J. J., \& Reynolds, W. M. (1999). Exposure to violence in young inner-city adolescents: Relationships with suicidal ideation, depression, and PTSD symptomatology. Journal of Abnormal Child Psychology, 27, 203-213.

McCubbin, H. I., Paterson, J., \& Glynn, T. (1987). Social support index. In H. I. McCubbin, A. I. Thompson \& M. A. McCubbin (Eds.), Family assessment: Resiliency, coping and adaptation: Inventories of research and practice (pp. 389). Madison, Wisconsin: University of Wisconsin Publishers.

McCubbin, M. A., McCubbin, H. I., \& Thompson, A. I. (1987). Family hardiness index. In H. I. McCubbin, A. I. Thompson \& M. A. McCubbin (Eds.), Family assessment: Resiliency, coping and adaptation (pp. 839). Madison, Wisconsin: University of Wisconsin Publishers.

McLoyd, V. C. (1998). Socioeconomic disadvantage and child development. American Psychologist, 53, 185-204.

Murata, J. (1994). Family stress, social support, violence, and sons' behaviour. Western Journal of Nursing Research, 16(2), 154-168.

Norvell, N., \& Towle, P. (1986). Self-reported depression and observable conduct problems in children. Journal of Clinical Child Psychology, 15(3), 228-232.

Parker, G., Gladstone, G., \& Chee, K. T. (2001). Depression in the planet's largest ethnic group: The Chinese. American Journal of Psychiatry, 158(6), 857-864.

Phillips, M. R., Yang, G., Zhang, Y., Wang, L., Ji, H., \& Zhou, M. (2002). Risk factors for suicide in China: a national case-control psychological autopsy study. The Lancet, 360(30), 1728-1736.

Resnick, M. (1997). Protecting adolescents from harm: Findings from the national longitudinal study on adolescent health. Journal of the American Medical Association, 278(10), 823-832.

Rogers, E., Moon, A. M., Mullee, M. A., Speller, V. M., \& Roderick, P. J. (1998). Developing the 'health-promoting school'-a national survey of healthy school awards. Public Health, 112, 37-40.

Rutter, M. (1984). Resilient children. Why some disadvantaged children overcome their environments, and how we can help. Psychology Today, March, 57-65.

Rutter, M. (1987). Psychosocial resilience and protective mechanisms. American Jouranl of Orthopsychiatry, 57, 316-331.

Rutter, M. (1990). Psychosocial resilience and protective mechanisms. In J. Rolf, A. Masten, D. Cicchetti, K. Nuechterlein \& S. Weintraub (Eds.), Risk and Protective Factors in the Development of Psychopathology. New York: Cambridge University Press.

Sawyer, M. G., Arney, F. M., Baghurst, P. A., Clark, J. J., Graetz, B. W., Kosky, R. J., et al. (2000). The Mental Health of Young People in Australia (No. 0642 44686 5). Canberra: Mental Health and Special Programs

Branch, Commonwealth Department of Health and Aged Care.

Scriven, A., \& Stiddard, L. (2003). Empowering schools: translating health promotion principles into practice. Health Education, 103(2), 110-118.

Shahar, G., \& Priel, B. (2002). Positive life events and adolescent emotional distress: in search of protective-interactive processes. Journal of Social and Clinical Psychology, 21(6), 645-668.

Shochet, I. M., Dadds, M. R., Holland, D., Whitefield, K., Harnett, P. H., \& Osgarby, S. M. (2001). The efficacy of a universal school-based program to prevent adolescent depression. Journal of Clinical Child Psychology, 30(3), 303-315.

Smith, C., \& Carlson, B. E. (1997). Stress, coping, and resilience in children and youth. The Social Science Review, 71(2), 231-256. 
Smith, C. A., Lizotte, A. J., Thornberry, T. P., \& Krohn, M. D. (1997). Resilience to delinquency. Prevention Researcher, 4(2), 4-7.

Smith, G. (1999). Resilience concept and findings: Implications for family therapy. Journal of Family Therapy, 21, 154-158.

Spilman, S. K. (2006). Child abduction, parents' distress, and social support. Violence \& Victims, 21(2), 149-165.

Stephens, T., Dulberg, C., \& Joubert, N. (1999). Mental health of hte Canadian population: A comprehensive analysis. Chronic Diseases in Canada, 20(3), 118-126.

Stewart, D., Sun, J., Patterson, C., Lemerle, K., \& Hardie, M. (2004). Promoting and building resilience in primary school communities: evidence from a comprehensive 'health promoting school' approach. International Journal of Mental Health Promotion, 6(3), 26-33.

Sun, J., \& Stewart, D. (2007). How effective is the health promoting school approach in building social capital in primary schools? Health Education,

Sun, Y. X. (2003). Overview of Children in China Journal of Family and Economic Issues, 24(4), 331.

Svanberg, O. G. (1998). Attachment, resilience, and prevention. Journal of Mental Health, 7(6), 543-579.

Tseng, W. S., Tao, K., Hsu, J., Chiu, J., Yu, L., \& Kameoka, V. (1988). Family planning and child mental health in China: the Nanjing survey. The American Journal of Psychiatry, 145(11), 1396-1403.

Wang, M. C., Haertel, G. D., \& Walberg, H. J. (1997). Fostering educational resilience in inner-city schools. In M. C. Wang, G. D. Haertel \& H. J. Walberg (Eds.), Children and Youth (pp. 119-140). Thousand Oaks, CA: Sage Publications.

Werner, E. E. (1989). High-risk children in young adulthood: A longitudinal study from birth to 32 years. American Journal of Orthopsychiatry, 59, 72-81.

Werner, E. E. (1992). The children of Kauai: Resiliency and recovery in adolescence and adulthood. Journal of Adolescent Health, 13, 262-268.

Werner, E. E. (1995). Resilience in development. Current Directions in Psychological Sciences, 4, 81-85.

Werner, E. E., \& Smith, R. S. (1982). Vulnerable but invincible: A longitudinal study of resilient children and youth. New York: Adams, Bannister, Cox.

World Health Organization. (1996). WHO information series on school health, Document 1: Strengthening interventions to reduce helminth infections-as an entry point for the development of health-promoting schools. Geneva: World Health Organization.

Zhang, M., Ji, J., \& Yan, H. (1997). New perspectives in mental health services in Shanghai. The American Journal of Psychiatry, 154(6), 55-58. 